\title{
O LIVRO DIDÁTICO E AS TEORIAS PEDAGÓGICAS
}

\author{
E. R. G. CARVALHO NETO \\ Instituto Federal de Educação, Ciência e Tecnologia do Rio Grande do Norte \\ eulalia.gusmao@ifrn.edu.br
}

Artigo submetido em novembro/2014 e aceito em novembro/2015

DOI: $10.15628 /$ holos.2015.2602

\section{RESUMO}

Este artigo tem por objetivo discutir a relação entre as teorias pedagógicas e os materiais escolares, em particular o livro didático. Fundamenta-se nas teorias que enfocam o ensino a partir de uma visão dialética e histórico-antropológica. Reflete sobre as contribuições históricas, sociológicas, filosóficas e psicológicas que articuladas constroem um campo de saber no qual floresce o fazer pedagógico. Considera que as teorias pedagógicas influenciam o livro didático com implicações que determinam sua estruturação metodológica e conceitual. Destaca a importância de o professor posicionar-se diante dos fundamentos educacionais e de suas implicações no processo de escolha do livro didático.

PALAVRAS-CHAVE: Educação escolar; Teorias pedagógicas; Livro didático.

\section{THE TEXTBOOK AND THE PEDAGOGICAL THEORIES}

\section{ABSTRACT}

This article aims to discuss the relationship between pedagogical theories and school material, particularly textbooks. It is based on theories which focus on the teaching process from a dialectical, historical and anthropological point of view. It reflects upon the historical, sociological, philosophical and psychological contributions which, once articulated, construct a field of knowledge in which the pedagogical decision making flourishes. Considers that pedagogical theories influence the textbooks in a way which determines their methodological and conceptual structure. Stresses the importance of the teacher's role of facing the educational foundations and their implications over the choice of textbooks.

KEYWORDS: School education. Pedagogical theories. Textbook.

\section{EL LIBRO DIDÁCTICO Y LAS TEORÍAS PEDAGÓGICAS}

\section{RESUMEN}

Este artículo tiene por objetivo discutir la relación entre las teorías pedagógicas y los materiales escolares, en particular el libro didáctico. Se fundamenta en las teorías que enfocan la enseñanza a partir de una visión dialéctica e histórico-antropológica. Refleja sobre las contribuciones históricas, sociológicas, filosóficas y psicológicas que articuladas construyen un campo de saber por medio del cual aflora el hacer pedagógico. Se considera que las teorías pedagógicas influyen el libro didáctico con implicaciones que determinan su estructuración metodológica y conceptual. Destaca la importancia del profesor posicionarse ante los fundamentos educacionales y de sus implicaciones en el proceso de elección del libro didáctico.

PALABRAS CLAVE: Educación escolar. Teorías pedagógicas. Libro didáctico. 


\section{INTRODUÇÃO}

Investigar a problemática do livro didático para a educação escolar tornou-se significativo para nós, na medida em que percebemos que dentre os vários elementos mediadores do processo de ensino e de aprendizagem, este material, apresenta-se como um dos principais, interferindo diretamente no trabalho pedagógico, já que, muitas vezes, é o único recurso do qual o professor dispõe como auxílio a sua prática docente.

Neste sentido, por considerarmos que concepções sobre o processo de ensino e de aprendizagem estão subjacentes na prática cotidiana da educação escolar, nos interessamos em discutir a relação existente entre as teorias pedagógicas, as práticas docentes e os materiais escolares, em particular o livro didático.

Para tanto, este artigo toma como referência uma pesquisa por nós realizada ${ }^{1}$ sobre a proposta pedagógica dos livros didáticos (livro do aluno e manual do professor) para o segundo segmento do Ensino Fundamental 5a a 8a séries - 60 ao 9 ano, adotados pelas escolas municipais de Natal nos anos de 2005 a 2007.

\subsection{Situando a problemática}

Em nosso país, o livro didático exerce um papel muito importante no contexto escolar, seja como instrumento de sistematização do conhecimento escolar, seja como elemento mediador da prática pedagógica, seja como instrumento de controle. Para fundamentar esse ponto de vista, consideramos, dentre outros, o fato de o Governo Federal, por meio do Fundo Nacional de Desenvolvimento da Educação (FNDE), ter instituído um Programa Nacional do Livro Didático (PNLD), que tem como objetivo prover as escolas do Ensino Fundamental das redes federal, estadual, municipal e do Distrito Federal com obras didáticas, paradidáticas e dicionários.

No município de Natal Estado do Rio Grande do Norte, a Secretaria de Educação e cultura, no ano de lançamento de um novo Guia, convoca, através de ofício enviado a cada um dos seus estabelecimentos de ensino, professores representantes por disciplina para reunião na qual são escolhidas as obras que deverão ser adotadas durante os três anos seguintes.

Cada uma das escolas, na época destinada à escolha do livro promove um estudo no qual os professores escolhem, para cada disciplina, duas coleções que serão apresentadas na reunião que contará com todos os representantes das escolas municipais. A Secretaria Municipal de Educação (SME) de Natal orienta o número máximo de coleções sugeridas pelas escolas para que a variedade de obras adotadas pela Rede Municipal não seja muito grande. Essa estratégia possibilita o remanejamento dos livros entre as escolas durante os três anos de adoção.

Desse modo, observamos que o livro didático, hoje distribuídos nas escolas públicas brasileiras, chama a atenção de todos os que, direta ou indiretamente, fazem a educação escolar. Nesse sentido, podemos considerá-lo como um produto cultural dotado de um elevado grau de complexidade, portador de um sistema de valores, de uma ideologia (BITTENCOURT, 1997). Estudar o livro didático, portanto, implica em considerarmos as diversas possibilidades de organização do saber escolar.

\footnotetext{
${ }^{1}$ Para elaboração de tese de doutorado defendida em 2007.
} 
Múltiplos são os olhares que podem conduzir este estudo. Podemos buscar definir a qualidade do livro didático a partir de sua apresentação física - cores, capa, papel, ilustração, tipo de letra, diagramação, dentre outros -, e/ou da forma como o conteúdo é apresentado fundamentação psicológica, pedagógica e científica dos conceitos apresentados, atualidade das informações e elementos ideológicos implícitos ou explícitos na apresentação das informações. No entanto, para elaboração deste artigo, optamos por evidenciar as teorias pedagógicas que dão suporte a elaboração do livro didático, analisando mais especificamente as orientações metodológicas sugeridas pelos autores.

Para fundamentar nossa análise, recorreremos aos estudos que refletem sobre o ensino escolar numa visão dialética e histórico-antropológica (GADOTTI, 2003; SEVERINO, 2004), e as teorias pedagógicas que marcam a história da educação escolar brasileira.

As teorias pedagógicas foram consideradas norteadoras da nossa análise pela importância desse conhecimento para o processo de sistematização do ensino. Um professor, consciente de suas escolhas, deve saber se posicionar - teórica e praticamente - diante das teorias educacionais que implicam na sua prática docente (Ghiraldelli, 2002). No caso da análise do livro didático essa implicação determina sua estruturação metodológica, especialmente no que diz respeito às atividades propostas.

Essas constatações despertaram a necessidade de fazermos uma análise da relação que se estabelece entre a educação escolar e a função do livro didático.

\section{A EDUCAÇÃO ESCOLAR E A FUNÇÃO DO LIVRO DIDÁTICO}

Considerar a escola contemporânea e seu papel no contexto da sociedade atual marcada pela tecnologia é um desafio para o professor. Uma nova transformação do saber de base gráfica vem revolucionando a cultura e a comunicação entre os homens. Contudo, a base das mudanças desta cultura não está na tecnologia em si, mas na forma como o acesso e a relação com o conhecimento se transformam a partir dela. A introdução dessa nova forma de comunicação modifica muito rapidamente a cultura, isso porque penetra em todas as áreas da sociedade transformando a maneira como o saber se dispõe ao sujeito. Desse modo nos perguntamos como definir e concretizar os pontos de encontro entre os avanços teóricos e metodológicos e as novas formas de encarar o ato educativo?

Compreendemos que a organização e a sistematização do conhecimento deve passar por profundas mudanças na escola e em especial na didática utilizada pelo professor. Este necessita estar atento às experiências já incorporadas pelos alunos, relacionando e dando sentido à trama na qual eles, alunos e professores, estão inseridos. Necessita, também, considerar as condições de aprendizagem dos alunos, suas preocupações, seus interesses e as finalidades sócio-políticas do ensino na sociedade contemporânea, pois, como afirma Pozo (2001, p. 32. Grifo do autor), "Estamos na sociedade da aprendizagem. Todos somos [...] alunos e professores. A demanda de aprendizagens contínuas e massivas é um dos traços que define a cultura da aprendizagem de sociedades como a nossa."

O livro didático aparece, no contexto acima mencionado, servindo de ponte entre as instâncias produtoras do conhecimento e o processo pedagógico, sistematizando e didatizando os saberes escolares através da exposição do conhecimento em áreas específicas, por meio de seções 
sistematicamente repetidas, do estabelecimento do programa, da organização dos conteúdos e da elaboração dos exercícios, pautando o dia a dia das aulas e, por vezes, assumindo as responsabilidades do professor.

No entanto, entendemos que o livro didático representa apenas parte do conteúdo e dos procedimentos que envolvem as práticas escolares de ensino e aprendizagem de uma disciplina. O que já é suficiente para torná-lo importante no processo de comunicação escolar.

Segundo Luckesi (1994, p. 145),

[...] o livro didático é um veículo de comunicação importante dentro do sistema de ensino; porém, não pode ser assumido acriticamente. Deve ser selecionado e utilizado de forma crítica, para que não sirva de veículo de conteúdos, métodos e modos de pensar que estejam em defasagem com a perspectiva que desejamos adotar.

Essa preocupação se torna ainda mais relevante quando percebemos que nesse material encontram-se valores que estão orientando o cotidiano escolar. Portanto, o professor deve ter claramente definido quais os pressupostos teóricos que orientam a sua prática no momento da escolha do livro didático.

Estudos apontam que os alunos necessitam, desde cedo, familiarizar-se com conceitos e problemas que possibilitem uma iniciação ao estudo dos conteúdos escolares. Para tanto, é necessário que o professor proporcione aos mesmos enxergarem o papel determinante do sujeito na produção da ciência, bem como as implicações da ideologia nessa produção.

Desse modo, cabe ao professor lançar mão de variados recursos e estratégias para elaboração de sua aula, incluindo o livro didático, que, em alguns contextos, aparece como única fonte de informação, impondo-se como necessidade pragmática tanto para as políticas de educação quanto para os próprios agentes pedagógicos. Assim, a escolha de um livro didático que promova a contextualização e a formação integral do indivíduo, comprometido com sua realidade social, cultural, política e econômica, torna-se imprescindível.

Pensamos que é necessário esclarecer que embora reconheçamos a importância do livro didático para as escolas brasileiras, não concebemos a prática pedagógica limitada ao uso desse material, pois se assim fosse, estaríamos deturpando um processo que deve ser marcado pela autonomia e criatividade do professor, pela compreensão e atitude diante daquilo que está sendo ensinado.

Portanto, reafirmamos que a utilização do livro didático deve ser norteada por uma reflexão teórica e metodológica que possibilite ao professor analisar e criticar as obras adotadas. Essa capacidade de análise, por sua vez, é decorrente de uma formação profissional que gere consciência crítica, gosto pela pesquisa, autonomia responsável e, acima de tudo, motivação, através do reconhecimento e da valorização social de sua profissão.

Ao refletirmos sobre a importância da escola e do papel do professor no processo de aprendizagem entendemos de forma mais sistematizada o contexto no qual o livro didático é utilizado e identificamos a necessidade de um estudo que evidenciasse a relação existente entre as teorias pedagógicas, as práticas docentes e os materiais escolares, em particular o livro didático. 


\section{OS SABERES PEDAGÓGICOS E O LIVRO DIDÁTICO}

Para entendermos as principais concepções que fundamentam os processos de ensino e de aprendizagem escolar que servem como suporte teórico para análise do livro didático optamos por considerar as contribuições históricas, sociológicas, filosóficas e psicológicas que juntas e articuladas constroem um campo de saber no qual floresce o fazer pedagógico e, conseqüentemente, o livro didático.

É importante destacar que embora alguns desses campos de saberes tenham sido sistematizadas em espaços e tempos semelhantes, a sequência de apresentação que adotamos neste artigo leva em consideração o espaço temporal em que cada um deles começou a influenciar a educação no Brasil.

Sabemos hoje que além de dominar os fundamentos e os conteúdos da disciplina que leciona, é imprescindível ao professor compreender como a mente opera e assimila o conhecimento. Essa importância evidencia-se, sobretudo na postura didática do docente que envolve, além das dimensões humana, cognitiva, emocional, cultural e político-social, a escolha das técnicas e dos instrumentos da prática pedagógica. Dentre esses instrumentos, encontra-se o livro didático.

[...] o livro didático caracteriza-se [...] por ser passível de uso na situação específica da escola, isto é, de aprendizado coletivo e orientado pelo professor. Por tais razões, o livro didático dirige-se, simultaneamente, a dois leitores: o professor e o aluno. [...] Por dever de ofício, o professor torna-se uma espécie de leitor privilegiado da obra didática, já que é a partir dele que o livro didático chega às mãos dos alunos (LAJOLO, 2013, WEB).

Desse forma, este material didático, aliado à ação docente, servirá de mediador na construção do conhecimento por parte do aluno. Assim, sentimos a necessidade de esclarecer as derivações didáticas das diferentes teorias pedagógicas que, ainda hoje, servem de alicerce teórico e epistemológico para a prática didático-pedagógica no Brasil.

Partimos do entendimento de que a educação escolar, nos seus mais variados aspectos, é um construto social historicamente determinado. Assim sendo, a ação educativa, prática intencional, sistemática e previamente planejada, mantém uma relação de dependência com os diferentes referenciais teóricos que orientam a prática docente e com as condições e vivências que definem a capacidade de elaboração pessoal de professores e alunos.

Nesse entendimento, as teorias pedagógicas objetivam interpretar, analisar e explicar como se dá o processo de aquisição do conhecimento escolar, cada uma com o seu enfoque epistemológico e metodológico. De fato, as concepções contribuem para a prática pedagógica, na medida que possibilitam ao professor estabelecer relações entre aquilo que é teorizado e a complexa e multifacetada prática escolar, permitindo escolhas diferenciadas.

Como afirma Ghiraldelli (2002, p.12) um educador é um professor que "sabe se posicionar - teórica e praticamente - diante das teorias educacionais". Sabe analisar as implicações dessas teorias, sabe quais são os objetivos do ensino sistematizado para sociedade da qual faz parte e, consequentemente sabe se posicionar frente a organização e sistematização da sua prática docente o que implica entre outros aspectos na escolha do livro didático. 
Propomo-nos, pois, a apresentar as características principais das pedagogias designadas como Tradicional, Escola Nova, Comportamentalista, Libertadora, Pedagogia com abordagem da Psicologia Genético-Cognitiva, Pedagogia Crítico-Social dos Conteúdos e Pedagogia com abordagem da Psicologia genético-dialética e seus aportes teóricos.

Esclarecemos que a escolha dessas pedagogias se deu em função de serem essas as mais recorrentes no discurso dos autores dos livros didáticos por nós analisados. Optamos por fazer um estudo descritivo das abordagens acima mencionadas, visando conceber suas implicações na elaboração do livro didático.

\subsection{Pedagogia Tradicional}

Embora tenhamos hoje vários estudos que demonstram a responsabilidade social da escola no que diz respeito, principalmente, ao desenvolvimento intelectual do aluno, através da construção da sua autonomia, a pedagogia tradicional resiste ao tempo e mantém-se em várias instituições de ensino que consideram ainda a aprendizagem como algo mecânico e o aluno um ser passivo, receptor dos conhecimentos. Estas características são impressas no processo de ensino e de aprendizagem seja através da postura do professor em relação aos alunos, seja através da escolha do material didático por ele utilizado.

Nessa pedagogia, os programas de ensino se encontram estruturados de acordo com uma sequência lógica e inflexível. Os manuais escolares, estritamente vinculados a esses programas, apresentam todo o conteúdo que o aluno deve saber. Minuciosamente organizados solicitam dos alunos a reprodução exata de seus conteúdos, tendo a memorização como consequência imediata. Na Pedagogia Tradicional o método de ensino é igual para todos, considera-se um aluno médio, ideal, sem levar em conta as variações e necessidades individuais. Como nos afirma Vial (1974, apud CARREÑO et al. 2000) o ensino tradicional desloca o real, fragmenta o tempo, é autoritário e desconhece as riquezas física, estética, moral, singular e social do educando.

Nesse contexto, o livro didático é bastante valorizado, pois serve de instrumento para a transmissão dos conteúdos que são trabalhados de forma linear, descontextualizada, fragmentada, acrítica, dando ao saber escolar um teor de conhecimento acabado. Isso explica por que, muitas vezes, são excessivamente expositivos e informativos. Os exercícios de fixação propostos normalmente vêm em forma de questionários repetitivos e enfadonhos, que servem tão somente para auxiliar o aluno na memorização dos conteúdos escolares, posteriormente reproduzidos através das provas orais e escritas, das atividades que solicitam do aluno apenas o desenvolvimento de funções mentais mnemônicas, à exemplo da metodologia adotada pela Igreja Católica desde os primórdios da chegada do jesuítas no Brasil para catequização dos nativos.

\subsection{Pedagogia da Escola Nova}

A Escola Nova é fruto de um movimento internacional, iniciado em fins do século XIX, que propunha uma mudança de foco para a educação escolar, contrapondo-se à escola tradicional. A criança com suas necessidades e capacidades passava a ser o centro dessa educação em que o fazer deveria preceder o conhecer. Nesse sentido, realizou-se uma mudança significativa na educação a partir do rompimento "com uma instituição escolar formalista, disciplinar e verbalista, e com uma pedagogia deontológica, abstrata e geralmente metafísica, alheia ao espírito da demonstração [...]" (CAMBI, 1999, p. 514) 
O avanço nos estudos da psicologia, em especial da psiquê infantil, aliado a novas pesquisas no campo educacional, apontou para a necessidade de profundas mudanças tanto no campo dos aspectos organizativos e institucionais, quanto dos aspectos ligados aos objetivos formativos e culturais.

$\mathrm{Na}$ educação escolar, qualidade e quantidade de ensino, passam a ser organizadas considerando-se a vida da criança, sua crescente evolução, seu interesse, sua liberdade e iniciativa. Toda a experiência, nos afirma Dewey (1979, p. 239), "por mais trivial que à primeira vista possa parecer, é capaz de assumir ilimitada riqueza de significação, amplificando sua série de associações percebidas."

Dessa forma, o princípio escolanovista prioriza atividades que possibilitam o contato da criança com ambientes externos através da manipulação, da experimentação e da descoberta em função do seu desenvolvimento. É por intermédio do meio que educamos e somos educados. No entanto, não podemos exigir da criança "que ela pense sobre as coisas ou que ela aja, sem suprila das condições indispensáveis para despertar e guiar o pensamento" (Dewey, 1978, p. 52). Seria necessário um meio educativo com estímulos e materiais selecionados de acordo com os instintos e impulsos que se queira desenvolver. A escola deveria definir seus objetivos a partir de atividades e necessidades do indivíduo que se quer educar.

Os conteúdos, nessa abordagem de ensino, são definidos a partir dos interesses e das necessidades dos alunos. A interpretação feita dos princípios escolanovistas levou muitos professores a considerar os conteúdos escolares como menos importantes que as atividades propostas.

Nos livros didáticos, essa teoria apresenta-se através da diluição dos conteúdos específicos da disciplina em conteúdos considerados, pelos editores, pelos autores e pelos professores, de interesse dos alunos. As propostas de atividades baseiam-se, na maioria das vezes, no estudo do meio, estudo de temas comuns e na pedagogia de projeto.

\subsection{Pedagogia com abordagem comportamentalista}

A proposta pedagógica alimentada pelos princípios da abordagem comportamentalista considera que a aprendizagem acontece por estímulo e resposta e que as contingências sociais definem o comportamento humano que reage a uma ação externa.

Nesse sentido, o comportamento passa a ser observado e controlado e a apresentação de informações realiza-se em pequenas etapas nas quais o aluno participa através da reprodução imediata de respostas. Reforços - positivos e negativos - conferidos ao indivíduo modelam o seu comportamento que, assim, pode ser objetivamente estudado. Alterações dos elementos ambientais e a proximidade temporal e espacial em relação ao comportamento que se pretende modelar tornam o reforço, utilizado de forma sistemática, cada vez mais eficaz.

Nessa perspectiva, a educação tem a função de modificar comportamentos seja na perspectiva da ética, das práticas sociais ou das habilidades básicas para o controle do ambiente cultural. A escola deve prever formas de condicionamentos para manter e instalar o comportamento por ela desejado. Assim, "para que o condicionamento se efetue é necessário que o organismo seja estimulado pelas consequências de seu comportamento" (Skinner, p. 45, 1974). 
Caberia, pois, ao professor executar o planejamento do processo de ensino-aprendizagem através da definição dos reforços que estimulem o aumento da probabilidade de uma resposta aprendida.

São dois os princípios que fundamentam os procedimentos didáticos dessa teoria,

[...] por um lado, a consideração da aprendizagem como um processo cego e mecânico de associação de estímulos, respostas e recompensas; por outro, a crença no poder absoluto do reforço sempre que se apliquem adequadamente sobre unidades simples de conduta. (SACRISTÁN, GOMÉZ, 2000, p.31)

A didática, segundo esse enfoque, limita-se à eficácia da técnica que prepara o ambiente e define objetivos operacionais com baixo nível de abstração, que, ao serem atingidos, reforçam uma conduta desejada e possibilitam uma avaliação precisa.

Nesse contexto, o papel do livro didático é basicamente oferecer exercícios, através dos quais o conteúdo fragmentado, é memorizado pelo aluno. Essa fragmentação explica-se pelos próprios fundamentos epistemológicos da teoria. O livro do mestre determina previamente o planejamento de ensino, bem como as respostas aos questionamentos elaborados para os alunos. Nas atividades propostas em sala de aula, as questões discursivas são eliminadas, procedimento que nega ao aluno toda e qualquer manifestação de caráter subjetivo. Evidenciam-se os conteúdos programáticos e as atividades que, na maioria das vezes são compostas por questões fechadas, visando condicionar respostas consideradas pelo professor como favoráveis.

\subsection{Pedagogia Libertadora}

A pedagogia libertadora, hoje influenciando todas as modalidades de ensino, aborda a prática pedagógica a partir de temas geradores, advindos das realidades social, econômica, política e cultural da comunidade na qual a escola está inserida. Alunos e professores discutem e analisam os problemas identificados com o propósito de entendê-los melhor e, ao mesmo tempo, buscar soluções conjuntas para resolvê-los. $O$ aluno aprende através de exercícios em que a compreensão, a crítica e a reflexão possibilitam a análise de uma situação-problema.

O trabalho escolar assenta-se numa metodologia que é ao mesmo tempo instrumento do educando e do educador e identifica o "conteúdo da aprendizagem com o processo mesmo de aprender" (FREIRE, 1980, p. 41).

Essa prática se concretiza no momento em que o professor, agente mediador do conhecimento, assume, dentre outros saberes, que ensinar exige respeito aos saberes dos educandos. "Por que não discutir com os alunos a realidade concreta a que se deva associar a disciplina cujo conteúdo se ensina [...]?" (FREIRE, 1996, p.33).

Desse modo, as assembléias, os relatos das experiências cotidianas, a pesquisa participante, os círculos de cultura, possibilitam o surgimento de problemas geradores importantes para a formação integral do aluno.

O repertório de conhecimento deve ser construído, sistematizado de forma coletiva, coparticipada. Na própria realidade estudada "há um universo de fala da cultura da gente do lugar, que deve ser: investigado, pesquisado, levantado, descoberto." (BRANDÃO, 1981, p. 25) 
Paulo Freire, que tem seus estudos centrados na educação de pessoas jovens e adultas, inicia sua crítica denominada de educação bancária ${ }^{2}$, fazendo uma avaliação dos livros didáticos, em especial das cartilhas de alfabetização, que se limitavam a apresentar uma visão de mundo exclusiva do dominador. Manuais que possuem um saber abstrato, imposto, que negam a possibilidade de se fazer uma relação entre a cultura elaborada, erudita, sistematizada e a cultura primeira construída no dia-a-dia do aluno. Por tudo isso os manuais acabaram por ser considerados como "uma espécie de roupa de tamanho único que serve pra todo mundo e pra ninguém" (BRANDÃO, 1981, p. 22)

Hoje podemos encontrar livros didáticos que, norteados pela pedagogia libertadora, apresentam o conteúdo a partir da problematização de temas geradores que refletem a realidade social e possibilitam uma investigação crítica sobre o entorno escolar. Em geral, não seguem os conteúdos tradicionais, apresentados pelas disciplinas escolares.

\subsection{Pedagogia com abordagem da Psicologia Genético-Cognitiva}

Com a abordagem da Psicologia Genético-Cognitiva temos, então, um modelo centrado na aprendizagem. Na medida em que o estudante, através de suas estruturas cognitivas, dos conhecimentos prévios, interesses e atividades, torna-se agente ativo de sua própria aprendizagem o conhecimento implica em uma reorganização de esquemas mentais. Desse modo, "o ensino deve promover a construção do conhecimento por parte do estudante e, em conseqüência, sua atividade cognitiva" (CAÑELLAS, CUBERO, p. 304, 2001).

Segundo Sacristan (2000), a assunção do postulado de que as estruturas cognitivas são resultantes de processos genéticos, permite-nos denominar essa teoria de construtivismo genético. A origem do conhecimento está na interação indissociável entre o objeto de conhecimento e o sujeito que conhece.

Alguns pressupostos didáticos podem ser extraídos da psicologia genético-cognitiva. Inicialmente, podemos considerar que os processos educativos, os quais têm como objetivo o desenvolvimento integral do aluno, devem "ser concebidos como processos de comunicação que estimulam os intercâmbios do indivíduo com o meio físico e psicossocial que o rodeia" (SACRISTAN 2000 , p. 36). A educação escolar deve dar particular atenção à atividade exercida pelo sujeito que aprende, pois esta, embora subordinada ao desenvolvimento, tem grande significação em todos os estágios do desenvolvimento das capacidades cognitivas.

Desse modo, o construtivismo genético aponta a necessidade de se considerar o conjunto de instrumentos cognitivos disponíveis ao aluno a partir da linguagem, a necessidade de se respeitar seus estágios evolutivos e seus ritmos de aprendizagem, contribuindo com a construção de estruturas cognitivas mais complexas e com a autoregulação do grupo classe, promovendo, assim, a autonomia grupal e individual.

\footnotetext{
2 “Na visão 'bancária' da educação, o 'saber é uma doação dos que se julgam sábios aos que julgam nada saber. Doação que se funda numa das manifestações instrumentais da ideologia da opressão - a absolutização da ignorância, que constitui o que chamamos de alienação da ignorância, segundo a qual esta se encontra sempre no outro." (FREIRE, 1997, p. 67)

3 Tradução nossa.
} 
Nesta perspectiva, o livro didático deverá, através da distribuição dos conteúdos, da sugestão de atividades, da escolha e disposição das ilustrações, respeitar os estágios de desenvolvimento dos alunos, oportunizar a organização de experiências, promover o conflito cognitivo, favorecer a cooperação, à troca de opinião, o debate, a discussão, a exposição de diferentes pontos de vista, permitindo que o aluno infira, construindo seu conhecimento. Pesquisar, organizar e relacionar informações, formar idéias a partir de vários dados, distinguir e diferenciar elementos para comparar são atividades privilegiadas no livro didático.

\subsection{Pedagogia Crítico-Social dos Conteúdos}

A pedagogia crítico-social dos conteúdos que tem como referência o materialismo histórico-dialético e considera que a atividade pedagógica deve fundamentar-se no desenvolvimento histórico-social do ser humano concede o fazer pedagógico como uma atividade associado à prática social concreta, em que todos os indivíduos envolvidos no processo de ensino e de aprendizagem escolar são entendidos como seres sociais e históricos.

Os teóricos dessa pedagogia ${ }^{4}$ apresentam a democratização da escola como um fator imprescindível aos alunos das camadas populares na formação de sua personalidade social e na sua organização enquanto coletividade. A escola cumpre com sua função social à medida que possibilita ao aluno apreender os conteúdos relevantes para a sociedade da qual ele faz parte. No entanto, cabe ressaltar que não basta que os conteúdos sejam apenas ensinados, posto que, ainda que bem ensinados, torna-se imprescindível que se liguem, de forma indissociável, a sua significação humana e social. (LIBÂNEO, 1989).

Ao mesmo tempo, para cumprir com sua função social, cabe à escola oferecer elementos que possibilitem uma análise critica da sua realidade imediata, ajudando o aluno a romper com a experiência difusa e estereotipada. A escola é o local onde se apresentam aos jovens modos de raciocínio rigoroso, pouco característico da juventude. Nessa perspectiva, na medida em que o conhecimento culturalmente elaborado proporciona ruptura com a cultura primeira, esses jovens precisam da orientação e da intervenção do professor. (SNYDERS, 1988).

Cabe, pois ao professor a responsabilidade de pensar o seu fazer cotidianamente, romper com os receituários e buscar alternativas para dinamizar sua prática pedagógica, considerando sempre a multidimensionalidade do processo de ensino-aprendizagem que envolve as dimensões técnica, humana e política. (CANDAU, 1983).

Esta última dimensão ganha contornos progressistas, imprimindo na formação do educador a necessidade da politização que possibilitará ao professor enxergar a ideologia que "inspirou o conhecimento usado e a prática desenvolvida na escola". (VEIGA, 1994, p.68).

O livro didático, organizado a partir dessa teoria, deve servir como estímulo "a professores e alunos no sentido de aguçar-lhes a capacidade criadora levando-os à descoberta e uso de novos recursos, através de sugestões múltiplas e ricas." (SAVIANI, 1984, p. 103). Desse modo não deve ser caracterizado como um conjunto de enunciado fechado, conclusivo. Deve considerar a cultura primeira como fonte motivadora para a construção da cultura elaborada e as atividades propostas devem possibilitar a participação dos alunos na análise e na crítica da realidade concreta. Dessa forma, as questões elaboradas devem favorecer respostas subjetivas, porém, embasadas na

${ }^{4}$ Saviani $(1984,1986)$; Libâneo $(1989,1994)$; Mello (1987) entre outros. 
cultura elaborada, pois, o conhecimento sistemático e politizado é segundo essa abordagem, condição necessária para a mudança social.

\subsection{Pedagogia com abordagem da Psicologia genético-dialética}

A abordagem da psicologia genético-dialética, parte do princípio de que aprendizagem e desenvolvimento se relacionam dialeticamente. O desenvolvimento é resultado da intrínseca relação existente entre as funções genéticas e as experiências realizadas pelo sujeito no seu contexto histórico-cultural, o qual é transformado e produzido pelo homem, através do trabalho.

Um dos grandes pilares dessa teoria é o conceito de mediação, no qual relação existente entre homem, natureza, homem é sempre mediada por produtos culturais - instrumentos e signos - e pelo outro. Instrumento é tudo aquilo que o homem utiliza para se relacionar com a natureza, ampliando sua ação sobre o meio. Os instrumentos não modificam apenas o meio, mas também o próprio homem que se transforma e modifica seu modo de agir. Segundo Vygotsky (1991, p. 62), “(...), a alteração provocada pelo homem sobre a natureza altera a própria natureza do homem."

No que se refere aos signos, Vygotsky (1991) afirma que, considerados como instrumentos psicológicos e sendo internamente orientados, servem como auxílio às atividades psicológicas do sujeito como lembrar, comparar, relatar, escolher, planejar, imaginar, dentre outros.

A linguagem, produto das relações historicamente construídas, constitui-se, pois, como o sistema de signos mais importante para os seres humanos por ser o principal instrumento de transmissão social.

O aluno, ao chegar à escola, partilha socialmente palavras que através de uma trajetória intelectual passam a constituir conceitos. O contato com a sistematização dos conteúdos, com material didático, com a organização do tempo, com a graduação das tarefas, possibilita ao aprendiz ultrapassar as observações superficiais e informais até chegar à organização conceitual do real. (NEMI, 1996, p. 41).

O professor, cúmplice desse processo, assume fundamental papel na articulação entre os conceitos espontâneos e os conceitos científicos, construídos sob a responsabilidade da escola. Deve atuar como o mediador que analisa as características dos conceitos selecionados e procura entender como esses são imbricados e se entrelaçam uns aos outros. (PENTEADO 1992).

Se considerarmos a importância da formação de conceitos e do desenvolvimento da autonomia por parte dos alunos, concluímos que o livro didático que se orienta pela teoria genético-dialética se apresentar como mais um elemento mediador entre as estruturas cognitivas dos alunos e a estrutura da área do saber que está sendo por ele veiculado. Para tanto, deverá ser estruturado de forma a possibilitar a relação entre o conhecimento sistematizado e o contexto sócio-cultural do aluno, apresentar conteúdos que possibilitem a apreensão dos sistemas de signos e significados embutidos nos saberes sistematizados ao longo da história da humanidade.

\section{CONSIDERAÇÕES FINAIS}

Quando investigamos a utilização do livro didático nas escolas, observamos que, por muito tempo, a apresentação dos conteúdos se deu numa perspectiva reducionista e com orientações 
metodológicas que impossibilitavam a emergência da construção de um conhecimento autônomo, necessário à valorização do saber escolar.

A esse respeito Eco (1980, p. 4) afirma que,

(...) muitas das nossas cãibras morais e intelectuais, muitas das nossas idéias correntes mais contorcidas e banais (e difíceis de morrer) nascem justamente dessa fonte [livro didático]. Portanto, a confiança que temos, instintivamente, no livro de leitura, não é devido aos méritos deste último, mas às nossas fraquezas, que os livros de leitura criam e alimentam.

Precisamos, pois, ficar atentos para a qualidade desse material que, nas escolas brasileiras interfere diretamente no processo de aquisição do conhecimento sistematizado, podendo ser decisivo para a qualidade do ensino e da aprendizagem formal.

Evidenciamos, pois, em nossa pesquisa que os Manuais do Professor não identificam literalmente a opção teórico-pedagógica feita por seus autores e que essa imprecisão em relação a tal opção interfere na qualidade do material elaborado. Entretanto, é possível ao professor familiarizado com as teorias pedagógicas observar os pressupostos implícitos em sua proposta metodológica.

Todos os autores dos livros didáticos por nós analisados reconhecem a necessidade de ruptura com o paradigma da educação tradicional, propondo em suas obras um ensino de Histórica que integre os conhecimentos em um todo significativo e em tempos diversos, que, por meio de sua contextualização, valorize a função social da escola e promova a construção e a reflexão crítica dos conceitos necessários à compreensão dos conhecimentos escolares.

No entanto, encontramos Manuais que oferecem uma vasta sugestão de materiais didáticos, uma vasta e atualizada sugestão bibliográfica de caráter didático-pedagógico, ao mesmo tempo em que apresenta no livro do aluno uma organização metodológica predominantemente baseada na pedagogia Tradicional. As atividades propostas são pouco desafiadoras e dá ao saber escolar um teor de conhecimento acabado, possibilitando ao aluno apenas o desenvolvimento de funções mnemônicas.

Temos a compreensão da importância das obras didáticas na educação da escola pública, tendo em vista a enorme carência dos alunos em relação ao acesso a materiais impressos. Ao mesmo tempo, percebemos que o conhecimento veiculado pelo livro não pode ser tomado como verdade absoluta, isenta de questionamentos, comparações, análises, contra-pontos.

Desse modo, cabe ao docente uma atenção redobrada no sentido de não permitir que o livro didático substitua-o na escolha dos conteúdos, na determinação de estratégias de ensino, em fim, na decisão de 'o que' ensinar e de o 'como' ensinar. Para tanto, percebemos a importância de uma ação consciente, um fazer legítimo e verdadeiro, no qual o professor saiba se posicionar de forma teórica e prática diante dos fundamentos educacionais e de suas implicações no processo de escolha do livro didático.

\section{REFERÊNCIAS}

1. BITTENCOURT, Circe (Org.) O saber histórico na sala de aula. São Paulo: Contexto, 1997. (Coleção Repensando o Ensino.) 
2. BRANDÃO, Carlos Rodrigues. O que é o método Paulo Freire. São Paulo: Brasiliense, 1981.

3. CAMBI, Franco. História da pedagogia. São Paulo: Fundação Editora da UNESP (FEU), 1999.

4. CAÑELLAS, Antoni J. Calom; CUBERO, Luis Núñez. Teoría de la educación. Madrid: Síntesis educación, 2001.

5. CANDAU, Vera Maria. A didática em questão. Rio de janeiro: Vozes, 1983.

6. CARREÑO, Miryam (Ed.) et al. Teorías e instituciones contemporáneas de educación. Madrid: Síntesis educación, 2000.

7. DEWEY, John. Vida e educação. 10. ed., São Paulo: Melhoramentos, 1978.

8. DEWEY, John. Democracia e educação. 4. ed., São Paulo: Companhia editora nacional, 1979.

9. ECO, Umberto. Mentiras que parecem verdade. São Paulo: Dummus, 1980.

10. FREIRE, Paulo. Pedagogia da autonomia: saberes necessários à prática educativa. São Paulo: Paz e terra, 1996.

11. FREIRE, Paulo. Conscientização: teoria e pratica da libertação: uma introdução ao pensamento de Paulo Freire. São Paulo: Moraes, 1980.

12. GADOTTI, Moacir. Concepção dialética da educação: um estudo introdutório. São Paulo: Cortez, 2003.

13. GHIRALDELLI, Paulo Jr. Didática e teorias educacionais. Rio de janeiro: DPA, 2002.

14. LAJOLO, Marisa. Livro didático: um (quase) manual de usuário. Disponível em: http://www. emaberto.inep.gov.br/index.php/emaberto/article/viewFile/1033/935 Acesso em 16 de jan. 2013.

15. LIBÂNEO, José Carlos. Democratização da escola pública: pedagogia crítico-social dos conteúdos. São Paulo: Loyola, 1989.

16. LUCKESI, Cipriano Carlos. Filosofia da educação. São Paulo: Cortez, 1994.

17. NEMI, Ana Lúcia. Didática da história: o tempo vivido: uma outra história? São Paulo: FDT, 1996

18. PENTEADO, Heloísa D.. Metodologia do ensino de história e geografia. São Paulo: Cortez, 1992.

19. POZO, Juan Ignácio. Aprendizes e mestres. Porto Alegre: ArtMed, 2001.

20. SACRISTÁN, J. Gimeno; GÓMEZ, A. I. Pérez. Compreender e transformar o ensino. Porto Alegre: Artmed, 2000.

21. SAVIANI, Dermeval. Escola e democracia. São Paulo, Cortez, 1984.

22. SEVERINO, Antonio Joaquim. A concepção filosófica do educar e a construção da filosofia da educação. In.: ROCHA, Dorothy (Org.). Filosofia da educação: diferentes abordagens. Campinas, SP: Papirus, 2004.

23. SKINNER, Burrhus Frederic. Ciência e comportamento humano. São Paulo: EDART., 1974.

24. SNYDERS, Georges. A alegria na escola. São Paulo: Manole, 1988.

25. VEIGA, IIma Passos A. A prática pedagógica do professor de didática. Campinas, SP: Papirus, 1994.

26. VYGOTSKY, Lev S. A formação social da mente. 4 ed., São Paulo : Martins Fontes, 1991. 